\title{
Indigenous health beliefs, attitudes and practices among VhaVenda: A challenge to the promotion of HIV/AIDS prevention strategies
}

\author{
FM Mulaudzi, D Litt et Phil \\ Associate Professor, North West University (Potchefstroom Campus)
}

\section{Keywords:}

Sexually transmitted diseases; HIV/ AIDS; indigenous knowledge; Vhavenda; cultural practices

\section{Correspondence address:}

Dr FM Mulaudzi

School of Nursing

Northwest University (Potchefstroom Campus)

Private Bag x 6001

Potchefstroom

2520

Tel : (018) 299-2396

Fax: (018) 299-2399

E-mail : mavis.mulaudzi@nwu.ac.za

\section{Abstract: Curationis $30(3): x-y$}

Currently, the syndromic management of HIV/AIDS is based on a biomedical model that focuses on the ABC (Abstain, Be faithful, Condomise) model. The ABC model overlooks the issue of indigenous cultural practices, sexual behaviours, knowledge and attitudes of the society. A grounded theory study was used for the research. The population for the research on which this article is reporting, was selected from the Vhavenda ethnic group using purposive sampling. In-depth interviews were held at the participants' own homes. The outcome of the study on which this article is reporting, may assist in identifying indigenous health beliefs, attitudes and practices that will assist in curbing the spread of HIV/AIDS. The findings revealed that cultural practices, such as premarital counselling, polygamy and widow inheritance, are believed to be influential in making women more susceptible to sexually transmitted diseases, including HIV/AIDS. The practice of abstinence, as emphasised at initiation schools, should be incorporated into current policies and preventative practices. The findings further demonstrate that policy-makers who formulated the HIV/AIDS strategy have limited knowledge of the health beliefs, attitudes and practices of the people they serve. They thus find it difficult to draw up promotion and prevention strategies that meet the needs of the community. It is therefore imperative that our health-care training curriculum be reviewed to make provision for the incorporation of sound and effective indigenous practices to reduce the spread of HIV/AIDS and to eliminate or refine practices that are harmful and detrimental to people's health. The cultural practices that were proved reliable and effective will be recommended for integration into health education.

\section{Introduction}

Sub-Saharan Africa has 25,8 million people living with HIV/AIDS; 5.6 million of these are in South Africa. More than 3 million people died of AIDS-related illnesses in 2005 (UNAIDS 2005:3). According to the report by the Department of Health (2004) regarding HIV/AIDS and syphilis sero prevalence in South Africa, infection levels among pregnant women are $20 \%$ and higher. Deaths among South Africans aged 15 years and older have increased by $62 \%$ and more than doubled in the 25-44 age group from 1997-2002. The prevalence of HIV infection among women of reproductive age is increasing worldwide. The literature indicates indirect evidence that the HIV epidemic in South Africa is raising the mortality levels of prime-aged adults.

Currently, the syndromic management of HIV/AIDS is based on a biomedical approach that focuses on the $A B C$ (Abstain, Be faithful, Condomise) model. Primary prevention therefore emphasises the use of condoms and restricting the number of sexual partners one should have. The use of anti-retroviral medication (ARV) as a form of secondary 
prevention is, however, also emphasised (Smith 1999:79). Despite the promotion of $\mathrm{ABC}$ strategies, mass health education and the roll-out of ARV treatment, the mortality and prevalence rates of HIV/ AIDS continue to increase (UNAIDS 2005:3). Gausset (2001:152) argues that the $A B C$ model overlooked the issue of indigenous cultural practices, sexual behaviours, knowledge and attitudes of the society. The prevalence of the epidemic despite current management strategies intensifies the need for healthcare professionals to make a conscious effort to increase their knowledge of the varied cultures within the communities that they serve. Giger and Davidhizar (1998:4) indicate that nurses need to devise some means of learning people's cultures in order to provide culturespecific or universal health-care practices. Helman (1996:152) and Lowdermilk, Perry and Bobak (1999:225) support the above views when they maintain that the norms and customs that are inherent in these indigenous cultures are fundamental in the day-to-day existence of the people concerned and may hold a key to the understanding of many aspects of people's lives, including the understanding of HIV/AIDS. Also inherent in culture is socially generated sexual behaviour that may be different for women and men. Some of these gender-based behavioural patterns and practices will be described in this article and may arguably be linked to the spread of HIV/AIDS.

Cultural and ethnic identity and folk beliefs play a decisive role in shaping people's perceptions, attitudes and practices regarding health care and illness. The understanding and incorporation of these concepts into conventional ways of health care could facilitate solving some of the problems facing professional health-care providers in South Africa. The outcome of the study on which this article is based, will assist in identifying cultural practices and beliefs that may assist in curbing the spread of HIV/AIDS. The practices that have proved to be reliable and effective will be recommended for integration into health education programmes. Awareness will be created around the dangers of cultural practices that are detrimental to women's health, especially those that put women at risk of HIV/ AIDS. Mechanisms to address cultural and indigenous practices that perpetuate women's vulnerability to HIV/AIDS will be recommended. This article aims to explore and describe indigenous beliefs, attitudes and sexual practices, which pose challenges to the prevention strategies of HIV/AIDS. These beliefs and practises can serve as points of departure in teaching clients about HIV/ AIDS.

\section{Literature review}

Indigenous health systems have provided care to people for many years, even before western health systems were integrated into traditional cultures. Abdool-Karim, Ziqubu-Page and Arendse (1994:1) state, "when an African patient consults a biomedical doctor, a third figure (this "third figure" being a traditional healer) is often present, albeit unseen". Furthermore, these authors assert that $80 \%$ of black patients visit traditional healers before or after they consult with a biomedical doctor. Although a variety of modern health-care options, like local government clinics, health centres and hospitals are available in Venda, patients continue to visit traditional healers. The incidence of visits to traditional healers is aggravated by the Vhavenda people's own beliefs and classification of diseases. The Vhavenda classify diseases according to causes. There are those diseases that are believed to be caused by supernatural powers or the gods (vhadzimu), and those that are caused through witchcraft and sorcery (Mabogo 1990:94; Mafalo 1997:63). The findings by Green (1994:122) on Swazi culture are relevant in this regard: the Swazi believe that there are diseases or conditions regarded as African (indigenous) and those that are foreign (western). In addition, they believe that indigenous diseases can be treated better by traditional healers whereas western diseases are treated more successfully by biomedical doctors.

\section{Sexuality education}

The health-care system of a society cannot be studied in isolation from other cultural aspects of that society. It is known that black people have their own beliefs and practices on how to prevent, diagnose and treat diseases, including sexually transmitted diseases. They have their own methods of sex education, including how to prevent teenage pregnancies (Madima 1996:25). Lumadi (1998:42) asserts that chiefs traditionally had powers to control traditional practices, such as initiation schools (rites of passage). New government structures such as the civic organisations and the Constitution have eroded the powers of the chiefs, for example Section 12(5)(a) of the Children's Bill, No. 70 of 2003 that is proposing that virginity testing be abolished. The shift from traditional practices to new medical practices left a vacuum that has not been filled to date.

\section{Effects of Colonialism on perceptions of health professionals}

Potter and Perry (2001:104) advance the view that folk practices from ancient times have been abandoned by modern healthcare belief systems. In support of this, Sodi (1997:20) argues that western psychology colluded with colonialism to denigrate indigenous knowledge systems. Although this is a psychological perspective, it becomes evident that a similar trend can be noted in medicine and nursing. It has been noted that health professionals often perceive indigenous practices as inadequate, primitive, superstitious, magical and quackery. As a result, the opportunities for understanding the values, norms, beliefs, needs and practices of women and men continue to be remote (Leininger 1999:64,65). Ethnic identity and cultural background of individuals influence their health-care attitudes, values and practices and could influence the policies and treatment strategies of diseases such as HIV/AIDS, thus enabling the national health-care system to achieve its goals and objectives.

\section{Marriage and family life}

Every family belongs to a community, and families are expected to live according to values and set familial norms that correspond with the mores of the particular society. Phaswana (2000:204) argues that, although Christianity is now a dominant religion, the African traditional value system dictates patterns of relationships. Amongst the Vhavenda, marriage has always been regarded a very important event in the life of a man/ woman. Traditional marriage involves the negotiation and payment of bride wealth (mamalo). Mamalo is the cattle or money paid to the family of the bride. According to Raliphada-Mulaudzi (1998:34), it was found in a study on nuptiality (marital) patterns of the Shona of Zimbabwe and conducted by Meekers (1994:256) that bride wealth payments consisted of 
several parts, which transfer specific rights to the groom, including sexual rights, the right to cohabit and the right to offspring born from this union. This view is supported by Raliphada-Mulaudzi (1998:21), who maintains that paying mamalo gives a man rights over his wife's body sexually, and also the right to determine the number of children he wants. In agreement with this notion, Mabogo (1990:60) states that amongst the Vhavenda, mamalo can be paid in instalments, with the last payments made after the birth of the first child. Raliphada-Mulaudzi (1998:22) observed that mamalo perpetuates women's subordination and therefore the chances of negotiating safe sex are limited in that situation. Polygamy is a common and acceptable practice among the Vhavenda. A community health nurse who taught about the practice of safe sex in Venda and who emphasised having one partner, indicated that he was shocked when a student reminded him that it is lawful and culturally acceptable to have more than one wife in the former Republic of Venda (Herbst 1990:23). It is therefore very important to know the cultural and sexual behaviour of a society before embarking on health education. Knowledge of a society's sexual behaviour, norms and practices may provide valuable information to the policy-makers, as it will enable them to formulate policies and strategies to combat diseases, for example HIV/AIDS, which are also culturally congruent, holistic and acceptable. The above-mentioned findings presented in previous studies therefore clearly indicate a disparity between current HIV policy on prevention methods and a sensitivity to cultural practices. This article therefore aims to provide insight into how the gap between policy and practice can be narrowed.

\section{Research design and methods}

A qualitative exploratory design was used to conduct the study on which this article is based. The grounded theory methodology served as the research design for the study (Strauss \& Corbin 1990:180). This approach was found to be appropriate as its roots are founded in the interpretive tradition of symbolic interactions. According to Talbot (1995:445), grounded theory examines the social context of human interaction. In addition, this methodology is well suited where there is little or no prior theory that has addressed the variable being studied in this approach. Theory is generated from and grounded in data that is systematically and simultaneously collected, coded, compared and analysed, using the constant comparative method (Polit \& Hungler 1999:195).

The population for the research on which this article is reporting, was sampled from the Vhavenda ethnic group. The Vhavenda, who are mostly found in the northern part of Limpopo Province, were chosen as they are among the few groups that still honour traditional cultural practises. The original Vhavenda known as Vhangona - have their language, culture and ancestral land. The population consists of over 1 million people. The Venda region also comprises several non-indigenous peoples, including Masingo, Vhalemba, Vhandalamo and Vhalaudzi.

The sampling technique that was used is supported by Strauss and Corbin (1990:180), who argue that the initial interviews and observational guides in grounded theory are only used as guidelines that help the researcher to have focus. Sampling is therefore an evolving process during the process of data collection as concepts emerge. Purposive sampling was used as a starting point because only people with the necessary information were selected. Furthermore, Powers and Knapp (1990:98) support this method of sampling, arguing that key information interviewing involves selective use of members of the culture who are particularly knowledgeable, insightful and articulated, or who have specialised knowledge that is not shared by the rest of the community (Streubert \& Carpenter 1999:103). Data was collected until saturation was reached. As data collection continued, theoretical sampling was used. Theoretical sampling dictates that comparison groups should be selected based on their potential for contributing to the emerging themes.

\section{Data collection}

Ethical considerations are important, as sexually transmitted diseases are considered a private and confidential matter. Permission to conduct the study was requested in writing from the Northern Province and the Vhembe regional authorities. Respect is always of great significance among the Vhavenda and, being a Muvenda herself, the researcher followed all the protocols necessary in gaining entry to the setting and gaining trust from the participants.

The study on which this article is based, drew subjects from men and women living in or near the chief's kraal because of their reputation for having more information than the rest of the group. The researcher went to the chief's kraal where she was given the names of people with relevant information. In-depth interviews were conducted at the participants' own homes. Information gathered was used to identify the traditional healers who were involved with the treatment of sexually transmitted diseases, and these were then interviewed. The traditional healers were targeted as they could shed more light on the subject. In-depth interviews were later conducted with three female herbalists, seven traditional healers, four females and three males. Two botanists were also interviewed the ages of participants ranged between $40-65$ years.

The question posed was:

What are the indigenous health beliefs, attitudes and practices that pose challenges to the promotion of $\mathrm{HIV} /$ AIDS prevention strategies?

Three research assistants from the University of Venda were employed to assist with the interviews. They were selected on the basis that they were from the Vhavenda ethnic group, i.e. they knew the language and culture of the participants. The assistants were postgraduate students from three different departments, namely Nursing Science, Gender Studies and Psychology. They were trained in interviewing and probing skills. A tape recorder was used to record the interviews and extensive notes were compiled during the interviews. The interviews were conducted in Tshivenda and later translated into English for a wider readability. The research assistants assisted in taking notes, transcribing data and analysing data.

\section{Measures to ensure trustworthiness}

For this study, the methods of trustworthiness in the evaluation of data quality as described by Lincoln and Guba (in Polit, Beck \& Hungler 2001:426) were used. The literature control of other studies also supported the findings. Furthermore, Truth value was enhanced by ensuring that the research assistants 
remained in the field for six months in order to enhance credibility. This encouraged free communication, and consequently the participants volunteered more sensitive information because of the increased rapport. In addition, the researcher went back to the participants or telephoned them for clarification where she felt there was a void in the information elucidated. Thorough field notes were taken directly after each interview to ensure dependability and confirmability. Investigator triangulation was achieved as more than one person was used to collect data. To facilitate transferability the context of the research was described thoroughly.

\section{Data analysis}

In grounded theory, data collection and data analysis occur simultaneously. Data was analysed according to the three steps of coding, as described by Strauss and Corbin (1990:54-247), namely open coding, axial coding and selective coding. Open coding is the first stage of the constant comparative analysis process to capture what is going on in the data, using the actual words of the participants. During axial coding, also known as level II coding, categories started emerging and in the process irrelevant data was discarded. The emerging categories were grouped and compared to ensure that they are mutually exclusive and that they do cover the behavioural variations (Munhall 2001:225). Lastly, selective coding, or the formation of theoretical constructs, was used. During this process, the researcher kept returning to the data, revising research questions and seeking out additional or missing data. This process was followed until different themes were generated.

The findings were discussed with participants themselves at the end of the research in order to get feedback from the participants and to ensure that the researcher had captured participants' own words and their meaning by discussing with them the interpretation of data (Krefting 1991:219; Talbot 1995:428).

\section{Interpretation and discussion of findings}

The findings of the study revealed that cultural practices such as sex education, premarital counselling, polygamy and widow inheritance, patriarchy and abstinence periods are believed to be influential in the prevention of the spread of sexually transmitted diseases, including HIV/AIDS.

\section{Sex education}

Respondents asserted that sex education was taught at initiation schools. Talking to your own child about sex education was not considered appropriate. This view is supported by fact sheets on HIV/ AIDS (Lindsay 2000:6-2) which state that there is a cloak of silence related to issues pertaining to sexual practises. Such matters are often associated with taboo and cause embarrassment, shame, guilt and rejection. The fact sheet goes further by emphasising that nurses and teachers also conform to this culture of silence regarding sexual practices as they are from the same cultures as the clients.

Children have to go through certain rites of passage. Boys and girls who have come of age are sent to initiation school (vhukombani for girls and thondoni for boys). Girls who have started experiencing their monthly periods, are warned that they are now of childbearing age and should therefore refrain from having sexual relations with boys. This started on the home front. During vhukombani, the girl is sent away for the sole purpose of sex education by "other parents". Talking about initiation schools, one of the respondents said:

"Men were taught about sex during an initiation called tshitambo, and for females there was u imbelwa. Girls were told that it is anathema to have sexual relations with a man before marriage. This made girls to be afraid to have sex before marriage, as they knew it was wrong to do so. So, all girls waited for marriage before having sex. Boys would also be told that if they had sex before marriage, they would suffer unending headaches, swollen genitalia and other frightful diseases."

Madima (1996:25) supports the above view when she maintains that a great deal of time at initiation schools is spent on sexual teaching. Girls are warned against being deflowered before marriage, and taught how to have sexual intercourse without "deflowering" taking place. Girls are therefore expected to stay virgins until they are married. Vaginal inspections (tshitavha) to find out whether the teenager is still a virgin, are also conducted. Gluckmann (in Green 1994:95) refers to the existence of a similar practise among the Zulu people. Chastity is highly valued and is part of the ethically enforced code. The girl-child knows that if she has lost her virginity before going to a ceremony called vhukomba (teenagehood) she is going to be a shame to her family, as virginity inspection will be conducted (Madima 1996:25). The practice is no longer common because of women's and children's rights. As one of the respondents said:

"If I were to say I wanted to do vaginal inspections on your children, you would be the first to say I want to bewitch them. In my day, we were inspected, not only for diagnostic purposes, but also to see whether one is still a virgin or not. This went on until wedding day."

It is asserted that the above practices, including abstinence from sexual intercourse, would save teenagers from contracting HIV/AIDS, and this view concurs with the ABC model. On the other hand, women who are campaigning for gender equality regard indigenous practices, such as initiation schools, as rituals that emphasise submissiveness and thus subjecting women to sexual abuse. In addition, practices such as virginity testing conducted on girlchildren, are seen as humiliating and a violation of girls' self- determination and self-esteem

\section{Premarital counselling}

Premarital counselling was found to be imperative among the Vhavenda. The prospective bride is taught how to behave towards her husband, including always consenting to intercourse with him. According to Lumadi (1998:43), premarital counselling starts during the last initiation school (domba), where the values of motherhood are inculcated to balance and maintain the stability of the social system. Premarital counselling is basically planned around teaching the prospective bride about the role of an African woman. Hay and Stichter (2003:53) describe the role of an African woman as that of a wife whose life is centred on her home and family. A woman proceeds to marriage from under the authority of her father to under that of her husband, which is equally not to be challenged. The respondents also emphasised that a woman was taught to respect her husband and to have no say in the running of the household, 
including sexual matters.

Regarding the protection of the husband to-be against diseases that the prospective brides may possibly have, one of the respondents said:

"Traditionally when a girl gets married, she does not immediately have sexual relations with her new husband. She first has to undergo vaginal inspections for the purpose of establishing her virginity, the existence of STDs and whether she is not pregnant by another man other than her husband. If found sick, she would first be treated before any sexual encounter."

When asked whether the same treatment was given to men, the respondent asserted that it would not be necessary, as men do not carry sexually transmitted diseases. There is a belief among the Vhavenda that sexually transmitted diseases are spread by women. Sexually transmitted diseases are therefore called " malwadze a vhasadzi" ("women's diseases). This belief is not held by the Vhavenda only a study conducted in Kenya by Moss, Bentley, Maman, Ayuko, Egessah, Sweat, Nyarang'o, Zenilman, Chemtai and Halsey (1999:95) on foundations for effective strategies to control sexually transmitted infections, revealed that sexually transmitted infections are termed "women's diseases".

\section{Polygamy}

There was no consensus on the issue of polygamy among respondents. Some indicated that they were against polygamy as it facilitates the spread of infection. Those in favour of polygamy indicated that it enabled the affected to trace contacts. This is substantiated by the following response:

"Men with more than one wives [sic] lived longer because a man who is always solving problems is always active and therefore does not grow old. This is what I was told by some old man. And again, this did not encourage the spread of STDs since the man was always indebted when it came to satisfying his wives. At the end of the circle, he needs to start again and so it goes. It also helped that the man did not sleep with strangers since he knew his wives. (Laughter). As for wives being tempted, it was just a matter of the wife being unfaithful. Even if she was the only wife she would still do it."

Gausset (2001:512) argues that it is not polygamy or monogamy that fuels the spread of HIV/AIDS, but fidelity or the practice of safe sex in extramarital relationships. $\mathrm{He}$ asserts that a polygamous family in which all partners are faithful to each other, or in which all partners practice safe sex is no more at risk than a monogamous family that has the same practices. In addition, this author also indicated that, because polygamy is no longer practised, men replaced the practice by having mistresses, which makes it difficult for one to trace contacts.

In South Africa, polygamous marriages are covered by the Recognition of Customary Marriages Act, No. 120 of 1998. This Act makes provision for the recognition of customary marriages. It is quite unfortunate that at the same time, the Act predisposes and increases women's vulnerability to HIV/AIDS. Men working in urban areas often marry two wives. The senior wife remains in the rural areas and is only visited during holidays, while the second wife lives with the husband in urban areas. This makes it possible for infections to be passed from one wife to the other. In polygamous relationships where a partner has extramarital affairs, she/he is likely to put others in the relationship in danger. Similarly, a monogamous relationship that is characterised by unfaithfulness, is just as risky.

\section{Widow inheritance}

Another customary practice that emerged during the interview was that of widow inheritance. According to this practice, the family of the diseased has the right to distribute the will of their son even if he was already married prior to his death. The husband's family chooses a new husband for the widow. If possible, her deceased husband's brother inherits her. The new husband will then inherit the widow, the children and any money or property that the deceased had. This practice is intended to protect the widow and the children, more especially the family name.

This type of practice makes people more vulnerable to sexually transmitted infections. Where the deceased died because of HIV/AIDS there is a chance that the surviving spouse will also be HIV positive. In that case an HIV negative brother will inherit the disease, thus spreading it to his other wives too. The adults will therefore die leaving children orphaned. Gausset (2001:512) defends the cultural practise of widow inheritance by asserting that women need the support of a man to raise children. This author therefore maintains that condom use should be emphasised and where people are suspecting HIV/AIDS as the cause of death, blood should be tested. Ironically, Gausset (2001:512) himself however commented on the dehumanising effect of blood tests, as in most instances only the widow is tested while the brother of the diseased is often reluctant to be tested.

\section{Abstinence periods}

According to the cultural values of the Vhavenda society, there are periods in women's lives during which they are not to have any sexual contact, namely the time of early widowhood, during the menopause, during menstruation, and during the postnatal period. This puts men in vulnerable positions as a result of having extramarital relationships. Thus, the chances of contracting HIV/AIDS and infecting the spouse are high. This view is supported by (Louistaunau, \& Sobo 1997:38). who indicated that women are considered dirty during menstrual period and postnatal periods.

\section{Patriarchy}

The Vhavenda group proved to be a patriarchal society, where men still want to be in control. The findings showed that male respondents were not keen on using condoms and verbalised that condoms limit sexual satisfaction. One respondent described a condom as " $a$ plastic that covers the penis, and thus making the penis unable to breathe". This belief is supported by research conducted by Gausset (2001:516) who reiterates that there is a belief that using a condom is like eating a sweet with its wrapper. The respondents further explained that suggesting condoms may subject a woman to physical assault, separation or divorce. Furthermore, inlaws and the woman's own parents may not support her if they are asked to mediate, and they may assume that she is practising infidelity.

These findings show the serious impact of gender inequality on the prevention of HIV/AIDS. African societies in general tolerate multiple sexual partners for men, but exert moral and social sanctions on 
women (Brycenson 1995:176). Bhatti and Fikree (2002:115) state that:

"Although the condom is seen at present as the only effective preventive measure against the sexual transmission of HIV/ STDs, for the majority of African women the suggestion that their partners or husbands use condoms is either seen as evidence of the woman's infidelity or perceived as defiance or insolence. At best, this may result in a breach of relationship; at worst, in the woman being beaten or abandoned."

In addition, the respondents in the current study showed that it is not acceptable for women to refuse their husbands sex, as women are seen as subordinate to men. Brycenson (1995:175) concurs that the rapid spread of HIV/AIDS is largely due to the powerless state in which African women find themselves when it comes to demanding fidelity or refusing sexual interaction. Obbo (in Brycenson 1995:176) adds that a woman who refuses sex is driving her husband to polygamy, be it of a formal nature in terms of new wives, or informally by having mistresses and girlfriends.

The above cultural practices portray women's subservience and silence in matters of safe sex. The sexual customs and norms of the Vhavenda put male needs and demands first in a marital relationship. By virtue of their patriarchal status and perceived roles in traditional society, men have power over women.

\section{Conclusions}

The indigenous health beliefs, attitudes and practices of the Vhavenda pose a challenge to the promotion of HIV/AIDS prevention strategies. The findings of the research on which this article is based, showed that cultural practices such as polygamy, influence the spread of HIV/ AIDS as they are in contradiction of the strategy of being faithful and sticking to one partner. Cultural beliefs and practices, including the high values placed on practices such as widow inheritance, increase women's vulnerability to HIV/AIDS. This makes it difficult for women to negotiate safe sex.

In addition, practices such as patriarchy and social acceptance of men's extramarital affairs, which is tolerated by social and cultural norms, perpetuate the subordination of women. These practices put women at the greatest risk of contracting HIV/AIDS. It was also evident in the research results on which this article is reporting that it is not easy for parents to discuss sexuality issues with their children.

Although the above findings hamper HIV/AIDS preventive strategies, there are also indigenous practices that can facilitate the prevention of HIV/AIDS. The research finding that concurred with the modern preventive strategies of HIV/ AIDS is that regarding the practice of abstinence that is taught at initiation schools. Initiation schools serve as medium for informing children about sexuality issues.

The findings of this study prove that the knowledge provided by this study may aid policy-makers in developing suitable and culturally sensitive policies.

\section{Recommendations}

Based on the research on which this article is reporting, the following recommendations are made:

Awareness of the dangers of cultural practices that are detrimental to women's health, especially those practices that put women at risk of HIV/AIDS, should be promoted. Examples of such practices include polygamy and widow inheritance. These practices, although embodied in customary law, need to be addressed and practised in a way that will not be detrimental to women's health. Sexual behaviour of the community needs to be aligned with HIV/AIDS strategies involving community stakeholders, such as religious groups, which could prove beneficial.

The issue of patriarchy should be addressed by challenging discriminatory practices against girls and women. Women need to be empowered to be assertive and to be able to negotiate safe sex. Interventions intended to empower women should be coupled with interventions to sensitise and educate men. In a patriarchal society, all interventions that do not involve men can be regarded as external interference and may be resented as men may feel it erodes their power or control over their wives.

Traditional leaders and traditional healers need to be included in committees responsible for planning strategies for improving the HIV/AIDS problem. This strategy should assist in incorporating the health beliefs and attitudes of the communities. Health-care professionals and policy-makers should also be trained as regards cultural knowledge, attitudes and practices in relation to HIV/AIDS.

Cultural practices that are harmless, such as abstinence and the value of initiation schools, should be integrated into modern health-care preventive strategies. It is recommended that the gap created by initiation schools be corrected by introducing sex education in the school curriculum. Sex education should take cultural needs, practices and beliefs into consideration, by emphasising abstinence instead of condom use. Education could also follow the initiation school curriculum, where the main focal point is on abstinence rather than on safe sex. The fact that youth can engage in safe sex often results in them having sex at a much earlier age and this subjects girls to vaginal tears that increase their susceptibility to sexually transmitted diseases including HIV/AIDS.

It is clear from the findings of the research on which this study is based, that the health beliefs, attitudes and practices of the community should be taken into consideration and put into proper perspective. Nurses need to be culturally competent in order to provide culturally competent care. Further research needs be conducted on other indigenous reproductive health issues that may impact on the spread, treatment and preventive strategies of HIV/AIDS.

Training curricula for health workers need to be designed to incorporate indigenous health-practice methods to enhance quality control and holistic health-care methods. This endeavour may promote prevention strategies that will facilitate and control the spread HIV/AIDS. This is important, as there is a need to provide ethno-nursing and culturally congruent care to the community. These guidelines may be used at basic and post-basic level, as well as by other teaching institutions.

In their endeavour to reduce the prevalence rate and the increased mortality rate of the population due to HIV/AIDS, health-care policy-makers should strive to formulate policies and management, which include society's indigenous beliefs and practices. Cultural 
beliefs and practices as illustrated by the research findings of the study on which this article is based, may serve as tools to enhance our strategies in health education. The tried and tested practices of the community, such as abstinence, should be emphasised in relevant policies. The issue of faithfulness is also of fundamental importance, particularly in cases where community members practise polygamy.

Culture is dynamic and capable of adapting to new conditions. It is therefore imperative that our health system be reviewed to make provision for the incorporation of sound and effective practices from indigenous cultures to reduce the spread of HIV/ AIDS and to eliminate or refine practices that are harmful and detrimental to our endeavour to deal with new challenges faced by society.

\section{References}

ABDOOL-KARIM,SS;ZIQUBU-PAGE, TT \& ARENDSE, R 1994: Bridging the Gap: Potential for Health Care Partnership between African Healers and Biomedical Personnel in South Africa. South African Medical Journal. 21:2-14.

BHATTI, LI \& FIKREE, FF 2002: HealthSeeking Behaviour of Karachi Women with Reproductive Tract Infections. Journal of Social Science and Medicine. 54: 105-117.

BRYCENSON, C 1995: African Women Hoe Cultivators: Lesson from Rural Africa for Feminist Theory and Development Practice. Oxford: Berg.

DEPARTMENT OF HEALTH 2004: National HIV/AIDS and Syphilis Seroprevalence Survey of Women attending Public Artenatal Clinics in South Africa. Pretoria, South Africa: Department of Health.

GAUSSET, Q 2001: Aids and Cultural Practices in Africa: The Case of Tonga (Zambia). Journal of Social Science and Medicine. 52: 509-518.

GIGER, JN \& DAVIDHIZAR, RE 1998: Transcultural Nursing Assessment and Intervention. St Louis: Mosby.

GREEN, EC 1994: AIDS and STDs in Africa: Bridging the Gap between Traditional Healing and Modern Medicine. Pietermaritzburg: University of
Natal Press.

HELMAN, CG 1996: Culture, Health and Illness. $3^{\text {rd }}$ edition. Boston: Wright.

HERBST, M 1990: Transcultural Nursing. Nursing RSA. 5(9): 20-23.

KREFTING, L 1991: Rigor in Qualitative Research: The Assessment of Trustworthiness. American Journal of Occupational Therapy. 45(3): 214-222.

LEININGER, M 1999: Qualitative Research Method in Nursing. Orlando: Grune \& Straton.

LINDSEY, E 2000: Facts Sheets on HIV/ AIDS. Geneva: World Health Organization.

LOUISTAUNAU, MO \& SOBOEJ 1997: The cultural context of Health, illness and medicine. London: Brgin and Garvey.

LOWDERMILK DL, PERRY SE, BOBAK IM 1999: Maternity Nursing. St Louis: Mosby.

LUMADI, TE 1998: Sociocultural Factors in the Family that are Significant for the Development of Giftedness in Vhavenda Children. Unpublished M-thesis. Pretoria: University of South Africa.

MABOGO, DEN 1990: Ethnobotany of the Vhavenda. Unpublished M-thesis. Pretoria: Pretoria University.

MADIMA, P 1996: The Development and Evaluation of Vhusha: A Culture Friendly Psychoeducational Programme for the Prevention of Pregnancy in Rural Venda. Unpublished M-thesis. Johannesburg: Rand Afrikaans University.

MAFALO, EP 1997: The Actual and Potential Roles of Indigenous Healers in the Mental Health Care Services in Rural Communities in South Africa. Unpublished M-thesis.Durban:UKZN.

MEEKERS, D 1994: Combining Ethnographic and Survey Methods: A Study of Nuptiality Patterns of the Shona of Zimbabwe. Journal of Comparative Family Studies. 25(3): 313-328.

MUNHALL, PL 2001: Nursing Research: A Qualitative Perspective. Norwalk: Appleton-Century-Crofts.
MOSS W, BENTLEY M, MAMAN S, AYUKO D, EGESSAH O, SWEAT M, NYARANG'O P, ZENILMAN, J, CHEMTAI A\& HALSEY N. Foundations for effective strategies to control sexually transmitted infections: voices from rural Kenya. AIDS Care,1999 Feb; 11(1):95-113.

PHASWANA, NS 2000: Marital Problems in Religiously Mixed Marriages Amongst the Vhavenda People of South Africa: An African-Christian perspective. Unpublished PhD-dissertation. Pretoria: University of South Africa.

POLIT, D \& HUNGLER, B 1999: Nursing Research Principles and Methods. $6^{\text {th }}$ edition. Philadelphia: Lippincott.

POLIT, D; BECK, CT \& HUNGLER, B. 2001: Nursing Research Methods, Appraisal and Utilization. $5^{\text {th }}$ edition. Philadelphia: Lippincott.

POTTER, PA\& PERRY,AG 2001: Basic Nursing, Essentials for Practice. Mosby: Elsevier.

POWERS, BA \& KNAPP, TR 1990: A Dictionary of Nursing Theory and Research. New Delhi: Sage Publication.

RALIPHADA-MULAUDZI, M 1998: Reproductive Health Rights of Women in Rural Communities. M-thesis. Pretoria: UNISA.

SMITH, S 1999: An Introduction to the Curative Aspects of Primary Health Care. Glenstatia: BM Printers.

SODI 1997: The Heart of Psychotherapy- A Journey into the Mind and Office of the Therapist at Work, G. Weinberg: Book Review. South African Journal of Psychology. 27: 714.

SOUTH AFRICA 1996: The Constitution of the Republic of South Africa Act 108. Pretoria Goverment Printers

SOUTH AFRICA 1998: Recognition of Customary Marriages, Act 120 of 1998. Government Gazette. Pretoria: Government Printers.

SOUTH AFRICA 2003: Children's Bill [B70-2003]. Government Gazette. Pretoria: Government Printers.

STRAUSS, A \& CORBIN, J 1990: Basics of Qualitative Research: 
Grounded Theory Procedures and

Techniques. Newbury Park, Calif: Sage.

STREUBERT, HJ \& CARPENTER, DR

1999: Qualitative Research in Nursing.

$2^{\text {nd }}$ edition. Philadelphia: Lippincott.

TALBOT, LA 1995: Principles and Practice of Nursing Research. St Louis: Mosby.

UNAIDS 2005: AIDS Epidemic updateDecember 2005. Geneva: UNAIDS. 